\title{
Article \\ Numerical Simulation on the Influence of Submerged Combustion on Splashing and Heat Transfer in TSL Furnace
}

\author{
Chen Song, Yuhua Pan *, Ping Ma, Ming Zhao and Tiancai Liu \\ School of Materials and Metallurgy, University of Science and Technology Liaoning, Anshan 114051, China; \\ schen200212@163.com (C.S.); marypma@hotmail.com (P.M.); 13614923317@139.com (M.Z.); \\ liutiancai0908@163.com (T.L.) \\ * Correspondence: 320153200140@ustl.edu.cn; Tel.: +86-130-5009-4115
}

Citation: Song, C.; Pan, Y.; Ma, P.; Zhao, M.; Liu, T. Numerical Simulation on the Influence of Submerged Combustion on Splashing and Heat Transfer in TSL Furnace. Metals 2022, 12, 328. https://doi.org/10.3390/ met12020328

Academic Editor: Gunter Gerbeth

Received: 14 January 2022

Accepted: 10 February 2022

Published: 13 February 2022

Publisher's Note: MDPI stays neutral with regard to jurisdictional claims in published maps and institutional affiliations.

Copyright: (C) 2022 by the authors. Licensee MDPI, Basel, Switzerland. This article is an open access article distributed under the terms and conditions of the Creative Commons Attribution (CC BY) license (https:/ / creativecommons.org/licenses/by/ $4.0 /)$.

\begin{abstract}
Bath smelting technologies based on top submerged lance (TSL) injection have been widely used for pyrometallurgical metal production and solid waste treatment. In this work, a twodimensional CFD simulation model of a pilot-scale $300 \mathrm{~kg}$ TSL furnace was established and applied to investigate the slag splashing phenomenon caused by submerged gas injection and combustion, with a special focus on the effect of submerged combustion on bubble formation, splash generation, splash distribution and heat transfer in the top space of the TSL furnace. The slag splash amount and distribution, and the temperature distribution characteristics inside the TSL furnace, especially under the influence of submerged combustion, were predicted, and influences of lance immersion depth and total injection gas flowrate on the splash behavior and heat transfer were investigated. As the lance immersion depth increases, more splashes are generated that distribute more evenly in the furnace top space and consequently heat transfer is enhanced. A larger injection gas flowrate generally increases the splash amount but the effect becomes weak when the injection gas flowrate exceeds a certain level, and there exists an appropriate range in injection gas flowrate for achieving the best heat transfer efficiency in TSL furnace.
\end{abstract}

Keywords: TSL furnace; submerged combustion; splashing; heat transfer; numerical simulation

\section{Introduction}

Metal production is a process involving high energy consumption and high pollution to the environment, in which large quantities of solid waste are generated. However, due to technical limitations, the majority amount of metallurgical solid wastes, such as slags produced in steelmaking and nonferrous metallurgy, dusts, sludge, ore tailings and red mud in aluminum production, etc., cannot be treated and recycled in a timely and effective manner; they have accumulated over a long time and piled up as mountain-like landfill that causes leaching of heavy metals in soil and water, resulting in increasingly serious environmental protection issues [1]. However, as the morphology of the metallurgical solid waste is complex, generally in varying sizes and irregular shapes such as powders, lumps, blocks, flakes, wires, etc., they are difficult to process using most of the existing metallurgical furnaces like direct reduction ironmaking furnaces, rotary hearth furnaces and kilns that have certain special restrictions on the charge materials. Usually, it is necessary to crush and grind the charge materials into fine powder, which can be injected through lances or granulated into pellets and sinter for charging, all of which increases the complexity and cost of the treatment processes. Nevertheless, in addition to applications for pyrometallurgical metal production, top submerged lance (TSL) bath smelting furnaces based on Sirosmelt, Ausmelt and Isasmelt technologies possess a great potential in processing the metallurgical solid wastes [2-4]. The raw materials can be fed directly through the furnace feed ports generally in original forms (lumps, blocks, flakes and wires). As to powders like dusts, they can either be granulated into pellets that can be charged via the furnace feed ports or injected through a TSL lance. Furthermore, in a TSL furnace air and 
fuel are injected in high flowrates into a molten bath through a multi-sleeve lance that is vertically immersed from the top into the molten bath to achieve strong bath agitation and generate intensive splashing. Therefore, the TSL furnace embodies the complex multiphase flow behaviors such as fluid mixing, heat and mass transfer, momentum transfer and chemical reaction [5]. Due to the submerged injection of large volumes of combustion gases into the melt bath, the TSL furnaces facilitate high heat and mass transfer rates through intensive bath agitation and splash generation, ensuring fast chemical reaction and bath homogenization. Therefore, the TSL furnaces have broad prospects in the treatment of metallurgical solid wastes due to their strong adaptability to feed materials, high efficiency and low impact on the environment [6].

However, while the splashes can enhance heat transfer and chemical reactions, they can solidify onto cooler places of the furnace, such as the furnace roof, and reduce the area for flue gas to be exhausted out of the furnace and cause operational and safety problems [2]. Thus, proper control of splash generation and its behavior in terms of splash height and size is crucial to maintaining smooth operation of TSL furnaces at sufficiently high intensity. In addition, TSL furnaces generally rely on utilizing the high-temperature flue gas produced by submerged combustion to heat the bath indirectly and, to a larger extent, to heat the in-flight splashes above the bath that eventually fall back to the bath due to gravity. However, the high-temperature flue gas may escape out of the furnace too early without sufficient heat exchange with the splashes causing heat loss brought away by the high-temperature flue gas. Therefore, heat transfer efficiency in the TSL furnace is worth studying and thus also included in the present modeling investigation. It is the aim of the present work to investigate splashing behavior of molten bath and heat transfer in the TSL furnace.

Due to the introduction of combustion, the complex structure of gas flow in the molten bath and the interaction between two phases, especially in the aspects of energy, mass and momentum exchange, it is very complex to fully explain the hydrodynamics of this process. Therefore, in the present study, Computational Fluid Dynamics (CFD) mathematical modeling techniques were used to simulate the interaction between gas jet and molten bath. Understanding and mastering the molten bath movement and splashing behavior can provide a theoretical basis for properly designing and efficiently and safely applying TSL furnaces for metal production and metallurgical solid waste treatment.

To date, experimental investigations and numerical simulations on the influence of top injection on the flow field and heat transfer in TSL furnaces have been carried out by a number of researchers. Liovic et al. [7,8] established a two-dimensional CFD model of gas injection from a top-submerged lance and simulated the phenomenon of bubble formation in the bath, bubble rise, splashed droplet formation and recoalescing with the bath. Pan and Langberg [9] established a two-dimensional CFD model to simulate the movement, deformation and breakup of large gas bubbles in an aqueous glycerol bath held in a physical model of a $300 \mathrm{~kg}$ pilot TSL furnace and the free surface flow caused by bubble rupture on the liquid bath surface, and studied the behavior of large bubbles and the mechanism of bubble rupture producing splashes. Wang et al. [10] studied the effects of gas flowrate and lance immersion depth on two-phase flow and bath temperature distribution in an Isa furnace through numerical simulation, but did not carry it out on a high-temperature immersion combustion system. Huda et al. [11] established a CFD numerical model of a cold air-water system to study the fluid flow phenomenon of top submerged lance injection of molten bath. Based on the multi-phase flow simulation of the conventional Eulerian-Eulerian approach, the effects of swirling and non-swirling flows, lance immersion depth and gas flow rate on the molten bath flow were qualitatively described. Subsequently, a pilot TSL furnace was established to study the bath mixing behavior and heat and mass transfer in the process of zinc fuming by immersion combustion [12]. Kolczyk et al. [13] carried out numerical simulation of slag-gas two-phase flow and heat transfer in a TSL furnace, and analyzed the influence of parameters such as lance immersion depth, gas flow rate and furnace shape change on velocity and temperature 
distributions in the liquid slag phase. Through numerical simulation of a cold model of Isa furnace, Yin et al. [14] concluded that adding swirler to the lance will significantly reduce the slag splashing quantity. Zhao et al. $[15,16]$ conducted water-model experiment and numerical simulation studies on the factors affecting the mixing time in a pilot Isa furnace and concluded that the mixing time was controlled by turbulent viscosity and velocity vectors. In addition, in their work the optimal lance diameter and lance immersion depth were obtained by investigating the mean velocity, phase volume fraction, splashing quantity and wall shear stress distributions. However, the impact of the actual industrial high-temperature submerged combustion working environment inside the Isa furnace was not considered. Based on a low temperature liquid metal bath, Obiso et al. $[17,18]$ performed cold physical modeling and CFD modeling to study the hydrodynamics of a TSL furnace and concluded that liquid splashing, surface tension of liquid, injection gas flowrate and lance positions were key factors influencing the TSL process. Sabah and Brooks [19] established a cold physical model to study the splashing phenomena in an oxygen steelmaking converter for different lance heights and gas flowrates. In their work the splash droplets were sampled to study the effect of the sampling positions on the splash droplet generation rate.

While the TSL furnace technology is well established, there have been few numerical simulation studies on submerged combustion and especially its effect on splash distribution and heat transfer in the top space above the bath in TSL furnaces. Therefore, in the present research, a two-dimensional CFD model of a $300 \mathrm{~kg}$ pilot TSL furnace was established and applied to investigate the phenomena of slag splashing and heat transfer caused by submerged gas injection and combustion, with a special focus on the effect of submerged combustion on bubble formation, splash generation, splash distribution and heat transfer in the top space of TSL furnace. The splash distribution and especially its ejection height generally determine the appropriate height of the TSL furnace. Therefore, by means of CFD simulation, an in-depth understanding on splash distribution characteristics and temperature field inside the TSL furnace operated at different lance immersion depths and gas flowrates can provide guidance to aid design and operation of the TSL furnaces for smooth and efficient metal production and treatment of metallurgical solid wastes.

\section{Numerical model}

\subsection{Model Geometry}

In this work, a two-dimensional CFD model of a $300 \mathrm{~kg}$ pilot TSL bath smelting furnace whose geometry, which is schematically shown in Figure 1a, was established and implemented for the numerical simulations by using ANSYS Fluent software package (Version 17.0, ANSYS Inc., Canonsburg, PA, USA). The model geometry is $0.3 \mathrm{~m}$ wide (in diameter) and $2 \mathrm{~m}$ high. The reason for choosing this size TSL furnace as the object of the present study was due to the availability of experimental observations reported by Pan and Langberg [9] on the same size physical model for use to validate the CFD model. In order to simplify the calculation, assuming the model is axisymmetric about the furnace axis, only half of the geometry (shown in the dotted box) was defined as computational domain and simulated. In addition, in order to reduce the computation requirement, only the part of the injection lance that is inserted into the liquid bath was included in the computation domain. Figure $1 \mathrm{~b}$ shows the computation grids defined for the computation domain. The injection lance was comprised of coaxial double-sleeve pipes with a center pipe inner diameter of $0.015 \mathrm{~m}$ and an outer pipe inner diameter of $0.03 \mathrm{~m}$. The computation domain was initially divided into two parts: The upper part is a gas phase domain, which was $1.7 \mathrm{~m}$ high; the lower part is a quiescent liquid phase domain (molten slag bath), which was $0.3 \mathrm{~m}$ high. The lance was immersed to a certain depth along the furnace axis into the liquid domain, and the immersion depth was set at $0.10 \mathrm{~m}, 0.15 \mathrm{~m}$ and $0.20 \mathrm{~m}$, respectively. 


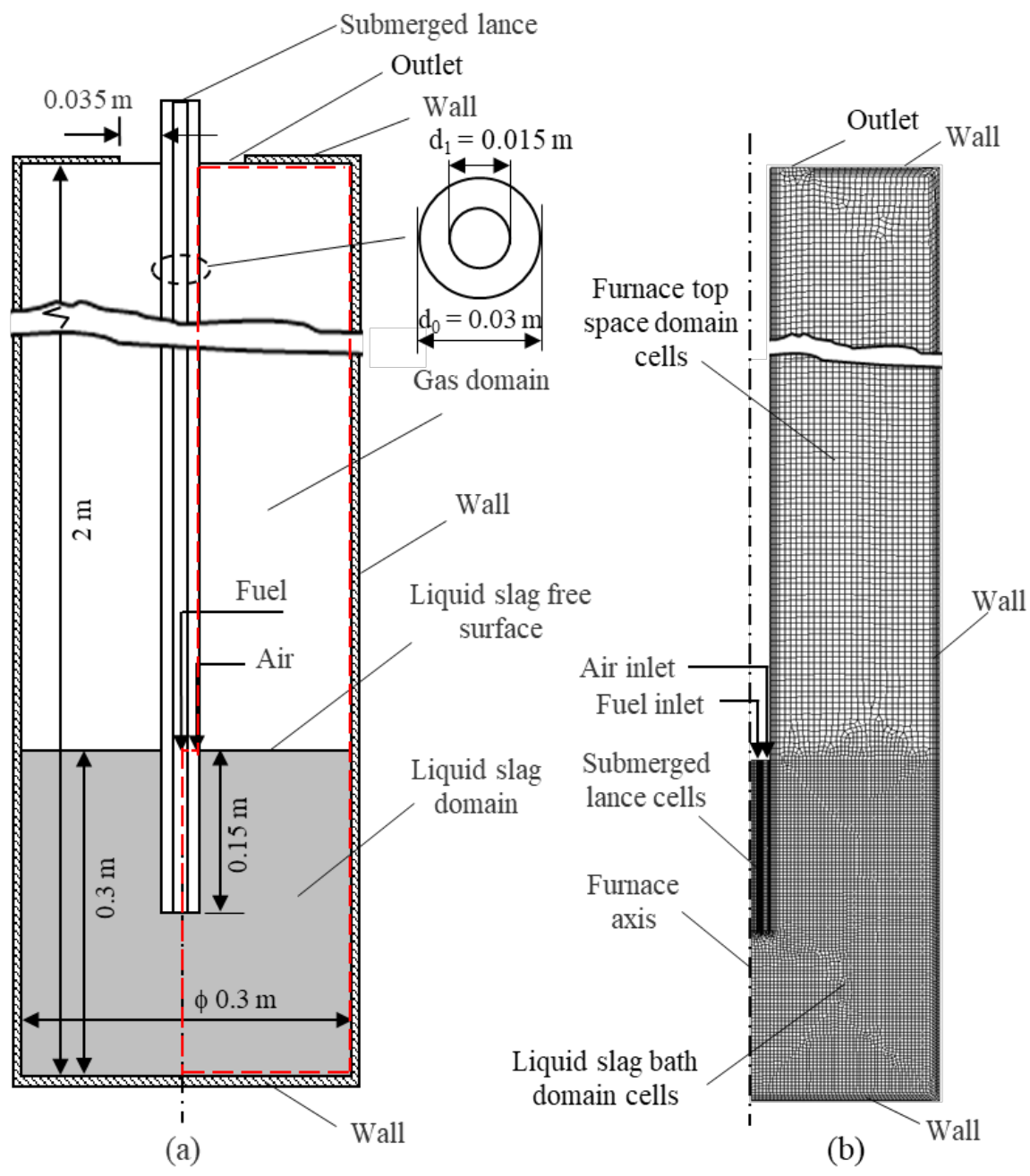

Figure 1. Schematic diagrams of (a) two-dimensional model geometry and computation domain of a pilot scale $300 \mathrm{~kg}$ TSL furnace with lance immersion depth of $0.15 \mathrm{~m}$ into the liquid bath and (b) computation grids.

\subsection{Numerical Model}

\subsubsection{Model Assumptions}

1. The furnace sidewall, bottom and roof are non-slip walls without thickness and heat loss to the external environment;

2. The lance is inserted from the top along the furnace geometric centerline, and the flow phenomenon is regarded as an axisymmetric two-dimensional flow;

3. The thickness of inner and outer pipes of the lance, which is actually $0.0015 \mathrm{~m}$, is neglected in the computation domain but the thermal resistance of the pipe wall is implicitly considered in the CFD model;

4. The variation in the depth of the molten bath due to charging and de-slagging operations are neglected; and

5. The phenomenon of possible slag foaming in the TSL furnace during operation is not considered.

\subsubsection{Governing Equations}

The volume of fluid (VOF) approach [20] was adopted to track the free interface between liquid and gas, which was realized by solving the continuity equation of phase volume fraction. 


\section{Continuity Equation}

For phase $q$, the continuity equation is as follows:

$$
\frac{\partial}{\partial t}\left(\alpha_{q} \rho_{q}\right)+\nabla \cdot\left(\alpha_{q} \rho_{q} v_{q}\right)=0
$$

The volume fractions of all phases should sum to 1, i.e.:

$$
\alpha_{\text {gas }}+\alpha_{\text {liquid-slag }}=1
$$

where $\alpha_{q}$ is the volume fraction of phase $q ; \rho_{q}$ the density of phase $q, \mathrm{~kg} / \mathrm{m}^{3}$; and the subscript $q$ denotes the gas phase or liquid slag phase.

\section{Momentum Equation}

The VOF model is used to solve momentum equations, Equation (3), in the computation domain where the velocity field is shared by all the phases (i.e., liquid and gas) [21].

$$
\frac{\partial}{\partial \mathrm{t}}(\rho v)+\nabla \cdot(\rho v v)=-\nabla p+\nabla \cdot\left[\left(\mu+\mu_{t}\right)\left(\nabla v+\nabla v^{T}\right)\right]+\rho g+F
$$

where $\rho$ is the mean density of fluid mixture, $\mathrm{kg} / \mathrm{m}^{3} ; p$ the pressure, $\mathrm{Pa} ; v$ the velocity vector, $\mathrm{m} / \mathrm{s} ; \mu$ the molecular viscosity, Pa.s; $\mu_{t}$ the turbulent viscosity, Pa.s; $g$ the acceleration due to gravity, $\mathrm{m} / \mathrm{s}^{2}$; and $F$ the volumetric force due to surface tension, $\mathrm{N} / \mathrm{m}^{3}$.

\section{Energy Equation}

Internal energy is solved from the energy balance equation, Equation (4):

$$
\frac{\partial}{\partial t}(\rho E)+\nabla \cdot[v(\rho E+p)]=\nabla \cdot\left(\lambda_{e f f} \nabla T\right)+S_{h}
$$

where $E$ is the specific internal energy, $\mathrm{J} / \mathrm{kg} ; \lambda_{\text {eff }}$ the effective thermal conductivity, $\mathrm{W} /(\mathrm{m} \cdot \mathrm{K})$; and $S_{h}$ the source term, $\mathrm{W} / \mathrm{m}^{3}$.

\section{Turbulence Equations}

The realizable $\mathrm{k}-\varepsilon$ model proposed in [22] is adopted to simulate turbulent flows. The transport equations of turbulent kinetic energy $\mathrm{k}$ and turbulent dissipation rate $\varepsilon$ are as follows:

$$
\begin{gathered}
\frac{\partial}{\partial t}(\rho k)+\nabla \cdot(\rho k v)=\nabla \cdot\left[\left(\mu+\frac{\mu_{t}}{\partial_{k}}\right) \nabla k\right]+G_{k}+G_{b}-\rho \varepsilon-Y_{M} \\
\frac{\partial}{\partial_{t}}(\rho \varepsilon)+\nabla \cdot(\rho \varepsilon v)=\nabla \cdot\left[\left(\mu+\frac{\mu_{t}}{\partial_{\varepsilon}}\right) \nabla \varepsilon\right]+\rho C_{1} S_{\varepsilon}-\rho C_{2} \frac{\varepsilon^{2}}{K+\sqrt{v \varepsilon}}+C_{1 \varepsilon} \frac{\varepsilon}{k} C_{3 \varepsilon} G_{b}
\end{gathered}
$$

and $\mu_{t}$ is the turbulent viscosity, which is computed as follows:

$$
\mu_{t}=\rho C_{\mu} \frac{k^{2}}{\varepsilon}
$$

where $k$ is the turbulent kinetic energy, $\mathrm{m}^{2} / \mathrm{s}^{2} ; \varepsilon$ the dissipation rate of turbulent kinetic energy, $\mathrm{m}^{2} / \mathrm{s}^{3} ; \sigma_{\mathrm{k}}$ and $\sigma_{\varepsilon}$ the turbulent Prandtl numbers for turbulence kinetic energy and its dissipation rate, respectively; $G_{k}$ the turbulent kinetic energy generation rate due to the mean velocity gradients, $\mathrm{W} / \mathrm{m}^{3} ; G_{b}$ the turbulent kinetic energy generation rate due to buoyancy, $\mathrm{W} / \mathrm{m}^{3} ; Y_{M}$ the rate of sink of turbulent kinetic energy due to the fluctuating dilatation in compressible turbulence, $\mathrm{W} / \mathrm{m}^{3}$; and $C_{1 \varepsilon}$ and $C_{2}$ the model constants.

Equations (5) and (6) are supplemented by the following auxiliary equations:

$$
C_{1}=\max \left[0.43, \frac{\eta}{\eta+5}\right]
$$




$$
\begin{gathered}
\eta=S \frac{k}{\varepsilon} \\
S=\sqrt{2 S_{i j} S_{i j}}
\end{gathered}
$$

5. Species Transport Model

Combustion of methane was simulated using a species transport model, in which the reaction rate appears as a source term that is governed by a large-eddy mixing time scale [23], which reads:

Transport equation for a chemical species $i$ :

$$
\frac{\partial}{\partial t}\left(\rho Y_{i}\right)+\nabla \cdot\left(\rho v Y_{i}\right)=-\nabla \vec{J}_{i}+R_{i}+S_{i}
$$

with

$$
\vec{J}_{i}=-\left(\rho D_{m, i}+\frac{\mu_{t}}{S c_{t}}\right) \nabla Y_{i}-\rho D_{T, i} \frac{\nabla T}{T}
$$

Eddy-dissipation reaction rate equation for a particular chemical reaction:

$$
\begin{gathered}
R_{i}=\min \left(R_{i, r}, R_{i, p}\right) \\
R_{i, r}=v_{i, r}^{\prime} M_{w, i} A \rho \frac{\varepsilon}{k} \min _{R}\left(\frac{Y_{R}}{v_{R, r}^{\prime} M_{w, R}}\right) \\
R_{i, p}=v^{\prime}{ }_{i, r} M_{w, i} A B \rho \frac{\varepsilon}{k} \frac{\Sigma_{P}\left(Y_{P}\right)}{\sum_{j}^{N}\left(v_{j, r}^{\prime \prime} M_{w, j}\right)}
\end{gathered}
$$

where $Y_{i}$ is the mass faction of species $i ; \vec{J}_{i}$ the diffusion flux of species $i, \mathrm{~kg} /\left(\mathrm{m}^{2} \cdot \mathrm{s}\right) ; R_{i}$ the net rate of production of species $i$ by chemical reaction, $\mathrm{kg} /\left(\mathrm{m}^{3} \cdot \mathrm{s}\right) ; S_{i}$ the rate of creation by addition from the dispersed phase, $\mathrm{kg} /\left(\mathrm{m}^{3} \cdot \mathrm{s}\right) ; D_{m, i}$ the mass diffusion coefficient for species $i$ in the mixture, $\mathrm{m}^{2} / \mathrm{s} ; D_{T, i}$ the thermal diffusion coefficient for species $i$ in the mixture, $\mathrm{m}^{2} / \mathrm{s} ; S c_{t}$ the turbulent $S c h m i d t$ number, whose default value is $0.7 ; \mathrm{A}=4.0$; and $\mathrm{B}=0.5$. The meanings of other symbols involved in the above equations can be found elsewhere [23].

Equations (1)-(6) and (11) are solved numerically by using ANSYS Fluent CFD simulation software package. For each numerical solution, SIMPLE numerical scheme was implemented for pressure and velocity coupling, and second order upwind schemes were applied to discretize the transport equations for momentum, turbulence, energy and reaction species. To keep the cell convective Courant number below 1 during the solution, the time step of each transient solution was set at $1.5 \times 10^{-5} \mathrm{~s}$.

\subsubsection{Boundary and Initial Conditions}

In the computation domain shown in Figure 1a, the lance is a double-sleeve steel pipe, whose inner pipe is supplied with methane at $300 \mathrm{~K}$ and outer pipe (annular gap) with air as oxidant also at $300 \mathrm{~K}$. As boundary conditions, the inlets of the pipes are set as velocity inlets, and the furnace opening is set pressure outlet. All the walls are regarded as no-slip boundary. As initial conditions, the temperature of the molten bath is set to $1573 \mathrm{~K}$ and the temperature of the furnace space above the quiescent molten bath to $300 \mathrm{~K}$.

\subsubsection{Model Parameter Conditions}

In the present work, the submerged combustion of methane, heat transfer and fluid flow inside the TSL furnace were numerically simulated under different lance immersion depths and injection gas flowrates. Details of the modeling conditions and parameters considered in this work are listed in Table 1, and the thermophysical properties of the fluids are given in Table 2. 
Table 1. Modeling conditions.

\begin{tabular}{|c|c|c|c|c|}
\hline $\begin{array}{c}\text { Calculation } \\
\text { Case No. }\end{array}$ & $\begin{array}{c}\text { Lance } \\
\text { Immersion } \\
\text { Depth (m) }\end{array}$ & $\begin{array}{c}\text { Natural Gas } \\
\text { Flowrate } \\
\left(\mathrm{Nm}^{3} / \mathrm{h}\right)\end{array}$ & $\begin{array}{l}\text { Air Flowrate } \\
\left(\mathrm{Nm}^{3} / \mathrm{h}\right)\end{array}$ & $\begin{array}{c}\text { Total Gas } \\
\text { Flowrate } \\
\left(\mathrm{Nm}^{3} / \mathrm{h}\right)\end{array}$ \\
\hline 1 & 0.15 & 6 & 50 & 56 \\
\hline 2 & 0.15 & 8 & 65 & 73 \\
\hline 3 & 0.15 & 10 & 85 & 95 \\
\hline 4 & 0.10 & 8 & 65 & 73 \\
\hline 5 & 0.20 & 8 & 65 & 73 \\
\hline
\end{tabular}

Table 2. Physical properties of fluids.

\begin{tabular}{ccccc}
\hline Material & Unit & Liquid-Slag & Air & Natural Gas \\
\hline $\begin{array}{c}\text { Density } \rho \\
\text { Viscosity } \mu\end{array}$ & $\mathrm{kg} / \mathrm{m}^{3}$ & 2590 & Compressible & Compressible \\
$\begin{array}{c}\text { Specific heat } \\
\text { capacity } C_{\mathrm{p}}\end{array}$ & $\mathrm{J} /(\mathrm{kg} \cdot \mathrm{K})$ & 0.269 & $1.79 \times 10^{-5}$ & $1.72 \times 10^{-5}$ \\
$\begin{array}{c}\text { Thermal } \\
\text { conductivity } \lambda\end{array}$ & $\mathrm{W} /(\mathrm{m} \cdot \mathrm{K})$ & 1945 & 1006.43 & $f(T)$ \\
\hline
\end{tabular}

\section{Results and Discussion}

\subsection{Model Validation}

The geometry of the TSL furnace simulated in the present work is the same as the physical model established by Pan and Langberg for the $300 \mathrm{~kg}$ pilot TSL furnace in CSIRO's Clayton laboratory [9]. The bubble shape and motion in the TSL furnace play an important role in the formation and distribution of liquid splashes. Therefore, it is rational and necessary to verify the predicted results of CFD simulations by examining the bubble behavior. As a means of model validation, Figure 2 shows the present model predicted generation and movement of large bubbles in a molten slag bath in the pilot TSL furnace in comparison with those in an aqueous glycerol bath visualized by Pan and Langberg [9] in their experiments on the physical model of the same TSL furnace. The bubbles in the experiments are represented by the black area in a white background (glycerin-air emulsion) of the captured video images. While the time intervals of the bubble behaviors predicted by the CFD model (on liquid slag and combustion gas system) and observed from the experiments (on aqueous glycerol and air system) do not correspond to each other, it can be seen from Figure 2 that the bubble deformation processes are similar to each other, which qualitatively verifies the accuracy of the present CFD model.
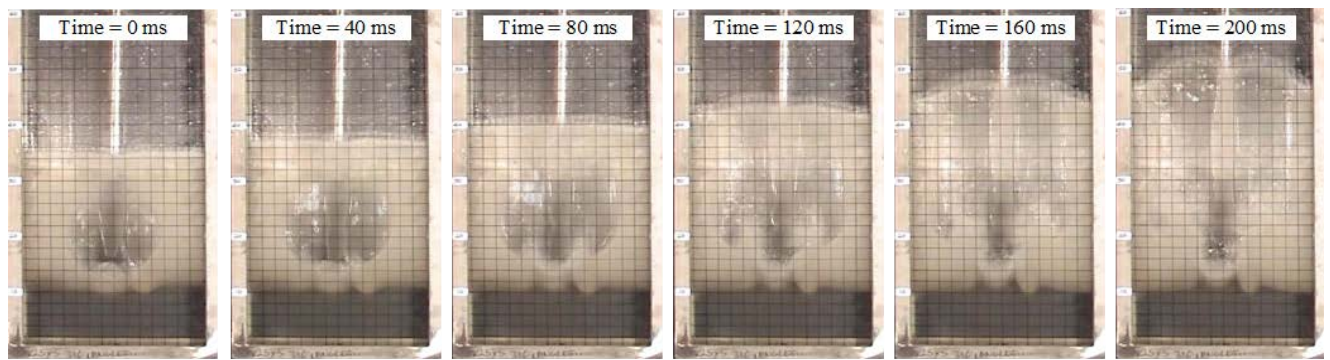

(a)

Figure 2. Cont. 


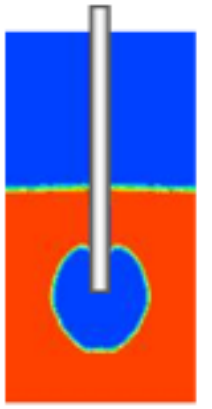

Time $=280 \mathrm{~ms}$

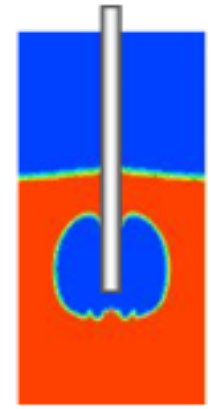

Time $=440 \mathrm{~ms}$

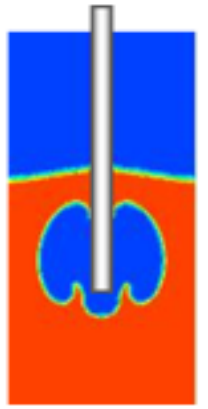

Time $=490 \mathrm{~ms}$

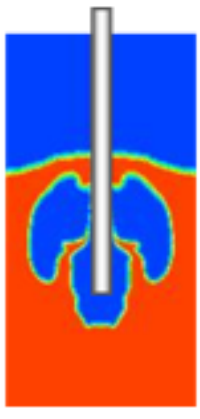

Time $=610 \mathrm{~ms}$

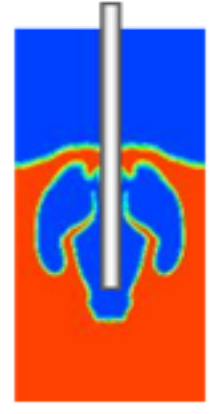

Time $=650 \mathrm{~ms}$

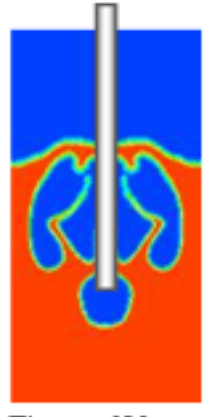

Time $=680 \mathrm{~ms}$

(b)

Figure 2. CFD model predicted generation and movement of large bubbles in liquid baths in a pilot TSL furnace in comparison with those observed from its physical model. (a) Captured video images from physical model experiments on aqueous glycerol and air system [9]; (b) Contour plots of liquid volume fraction simulated by present CFD model on liquid slag and combustion gas system.

\subsection{Splash Formation and Distribution}

Figure 3 shows the bubble behaviors in TSL furnace under the same operating conditions (lance immersion $0.15 \mathrm{~m}$ and injection gas flowrate $73 \mathrm{Nm}^{3} / \mathrm{h}$ ) predicted by CFD model with and without consideration of combustion. As shown in Figure 3, the bubble shapes generated in the TSL furnace with and without combustion are similar, but the bubble size and the splash height and distribution are obviously very different. Due to combustion, the bubbles are larger, and the splash height when the bubble breaks is much higher than that without combustion. Therefore, bubble behavior and splash generation in the high-temperature combustion system in the TSL furnace is closer to those in the actual industrial process for metal production using the TSL furnace, so there is more meaningful and reference value to carry out the TSL combustion numerical simulation study to guide the design and operation of the TSL furnace.

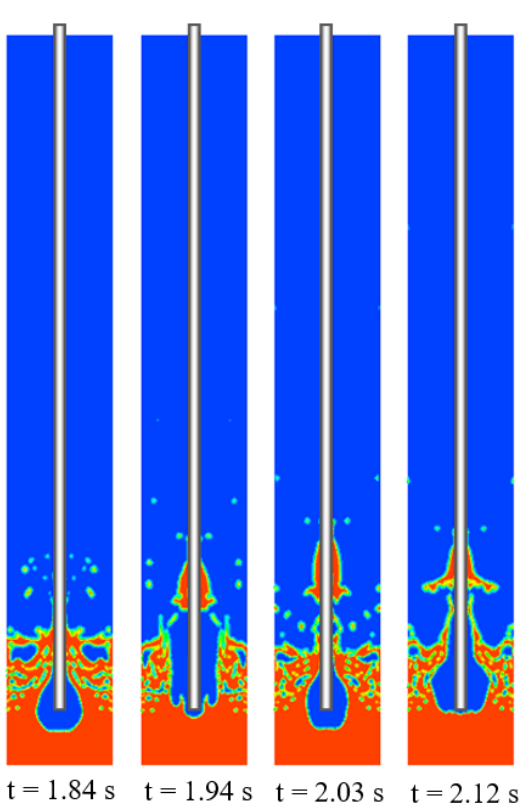

(a)

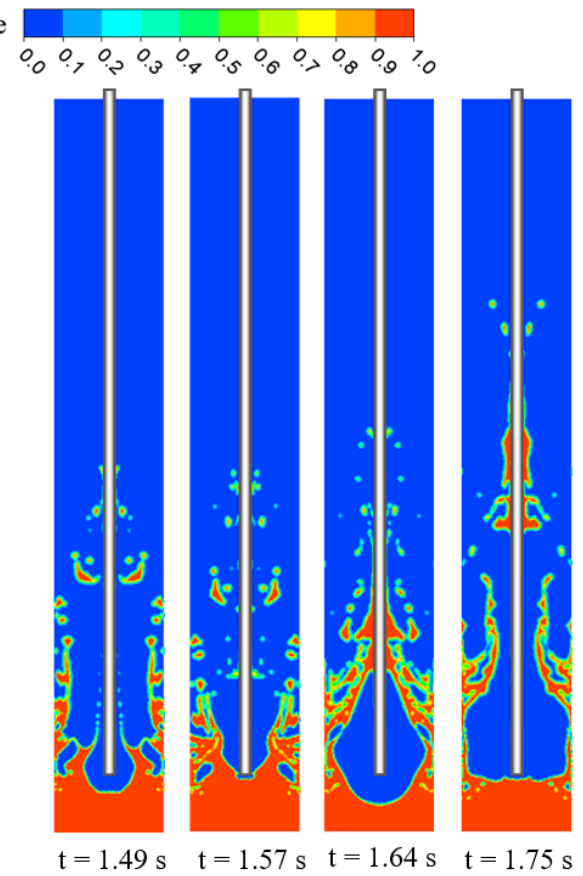

(b)

Figure 3. Bubble behaviors in TSL furnace simulated with and without combustion under the same operating conditions (lance immersion $0.15 \mathrm{~m}$ and injection gas flowrate $73 \mathrm{Nm}^{3} / \mathrm{h}$ ). (a) Without combustion; (b) With combustion. 
Figure 4 shows the CFD model predicted process of slag splashing in the TSL furnace for operation conditions of lance immersion depth $0.15 \mathrm{~m}$ and total injection gas flowrate (hereinafter, injection gas flowrate for short) $73 \mathrm{Nm}^{3} / \mathrm{h}$. The submerged combustion of methane takes place inside the bubbles connected to the lance nozzle exit. Initially the bubbles are small and elliptical (Figure 4a). As the injection and reaction proceed, a large amount of flue gas is produced. The bubbles bloat rapidly, which impacts the liquid phase of the bath (Figure $4 \mathrm{~b}$ ). As the bubbles continue to expand and rise upward, they eventually break up the bath free surface (Figure $4 \mathrm{c}$ ). The bubble bursts and releases energy to drive the movement of the liquid slag. The upward movement of the slag leads to parts of the slag being ejected into the top space of the furnace forming splashes (Figure $4 \mathrm{~d}$ ). After the splashes reach maximum heights, due to gravity they eventually fall back to the bath. Then, the next cycles of a similar process follow (Figure $4 \mathrm{e}-\mathrm{h}$ ). Therefore, it can be understood that the slag splashing caused by methane immersion combustion is generally a cyclic process of four consecutive steps: (i) Combustion produces flue gas to form large bubbles; (ii) bubble expansion impacts the liquid slag; (iii) bubble breakup drives the motion of slag to cause splashing; and (iv) after the splashes reach maximum heights, the gravity drives the splashed slag to fall back to the bath.

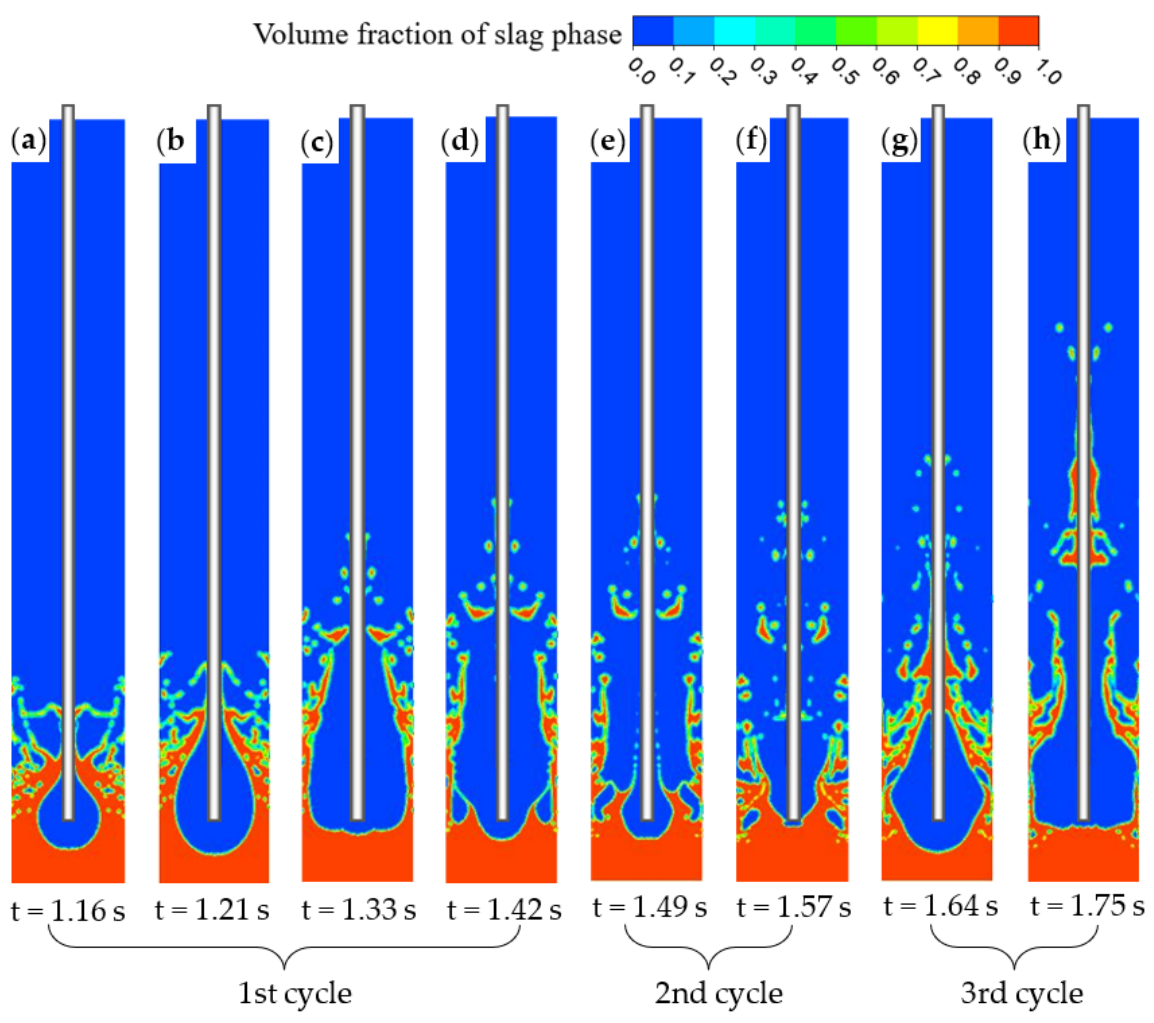

Figure 4. (a-h) Process of slag splashing in TSL furnace predicted by CFD model for lance immersion depth $0.15 \mathrm{~m}$ and injection gas flowrate $73 \mathrm{Nm}^{3} / \mathrm{h}$.

\subsection{Influence of Operation Parameters on Slag Splashing}

3.3.1. Influence of Lance Immersion Depth on Splash Amount and Distribution

Figure 5 shows the splash distribution in the pilot TSL furnace for the same injection gas flowrate $\left(73 \mathrm{Nm}^{3} / \mathrm{h}\right)$ and different lance immersion depths when the splash behavior reaches a quasi-steady state. As the lance immersion depth increases, the gas phase penetration takes place in a larger volume of the bath and thus generates more splashes that distribute more uniformly in the furnace top space. When the lance immersion is sufficiently deep (e.g., $0.20 \mathrm{~m}$ ), the bath stirring becomes so intense that there is almost no dead zone, as depicted in Figure 5c. Therefore, the lance immersion depth is an important factor affecting the mixing dynamics of molten bath. 


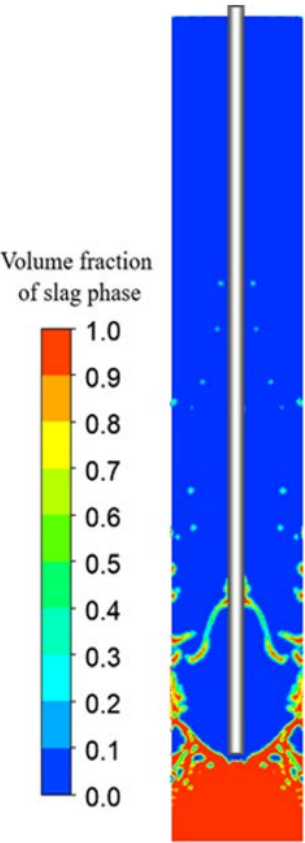

(a)

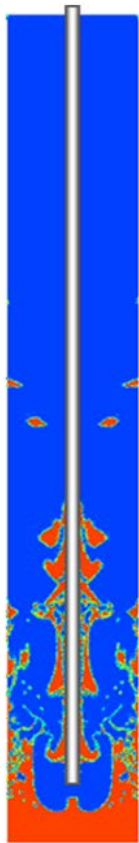

(b)

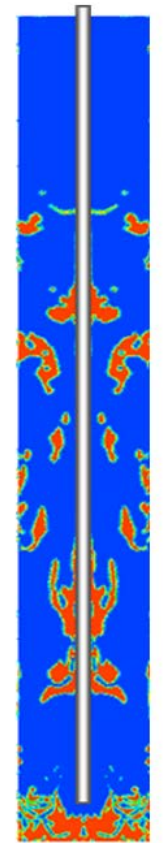

(c)

Figure 5. Splash distribution in TSL furnace for the same injection gas flowrate $\left(73 \mathrm{Nm}^{3} / \mathrm{h}\right)$ and different lance immersion depths. (a) $\mathrm{H}_{\mathrm{L}}=0.10 \mathrm{~m}$, (b) $\mathrm{H}_{\mathrm{L}}=0.15 \mathrm{~m},(\mathbf{c}) \mathrm{H}_{\mathrm{L}}=0.20 \mathrm{~m}$.

Figure 6 shows variation of average liquid volume fraction along the height of the furnace for the same injection gas flowrate $\left(73 \mathrm{Nm}^{3} / \mathrm{h}\right)$ and different lance immersion depths. If the furnace is designed too high, the lance will be too long, so that the investment cost will be too high and the smelting operation will be more difficult. On the other hand, if the furnace height is too short, slag splash will hit and stick to the furnace roof and exhaust duct, which will interfere operation and cause safety problems. Therefore, it is of great significance to predict and control the slag splashing height through CFD simulation to guide the furnace design and operation. It can be seen from Figure 6 that, for the same injection gas flowrate, the splash distribution along the furnace height direction is significantly influenced by the lance immersion depth. Generally, a deeper lance immersion depth leads to more and higher splashes. For instance, when the lance immersion depth is controlled at $0.10 \mathrm{~m}, 0.15 \mathrm{~m}$ and $0.20 \mathrm{~m}$, the maximum splashing height reaches about $1.05 \mathrm{~m}, 1.18 \mathrm{~m}$ and $1.6 \mathrm{~m}$, respectively. Therefore, manipulating the lance immersion depth is an effective means of controlling the splash amount and maximum height.

Figure 7 shows an index of the total amount of slag splashes remaining above the bath (i.e., the area below each curve shown in Figure 6) as a function of the lance immersion depth for the same injection gas flowrate. It can be seen from this figure that with the deepening of the lance immersion depth, the amount of slag splashing increases. When the lance immersion depth is increased from $0.10 \mathrm{~m}$ to $0.15 \mathrm{~m}$, the splash amount index increases from $0.0398 \mathrm{~m}^{2}$ to $0.0433 \mathrm{~m}^{2}$ with the increment being $0.0035 \mathrm{~m}^{2}$; when the lance immersion depth is further increased from $0.15 \mathrm{~m}$ to $0.20 \mathrm{~m}$, the splash amount index increases from $0.0433 \mathrm{~m}^{2}$ to $0.0448 \mathrm{~m}^{2}$ with the increment being $0.0015 \mathrm{~m}^{2}$. 


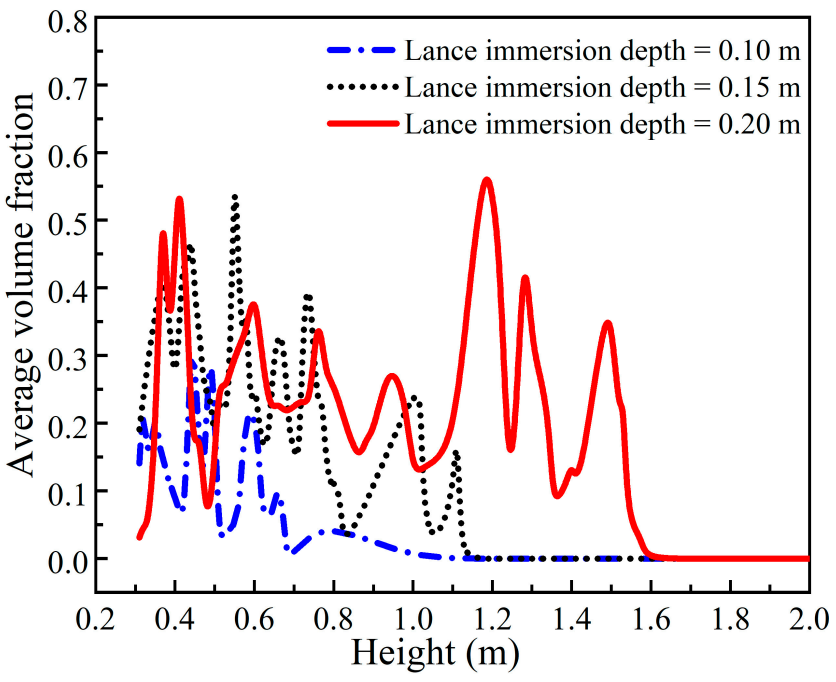

Figure 6. Influence of lance immersion depth on distribution of average volume fraction of splash along furnace height for the same injection gas flowrate $\left(73 \mathrm{Nm}^{3} / \mathrm{h}\right)$.

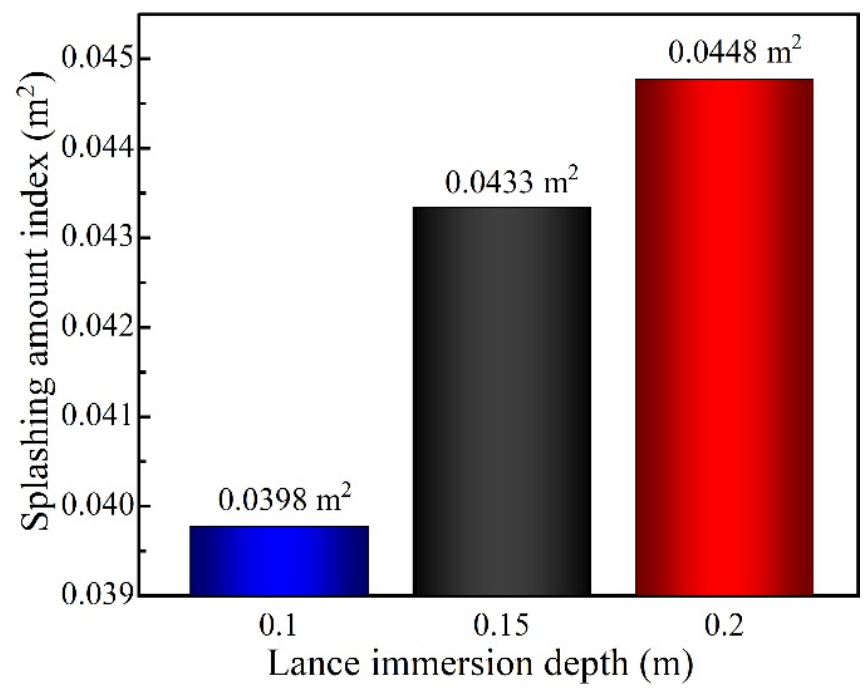

Figure 7. Effect of lance immersion depth on slag splashing amount index.

Figure 8 shows variation in the distribution characteristics of axial velocity of flue gas and splash along the furnace radius and on the horizontal plane at different heights above the quiescent bath surface for the same injection gas flowrate $\left(73 \mathrm{Nm}^{3} / \mathrm{h}\right)$ and different lance immersion depths. When the lance immersion depth is $0.10 \mathrm{~m}$, the maximum velocity on the horizontal plane of $0.2 \mathrm{~m}$ above the quiescent bath appears close to the lance. With the increase of the lance immersion depth, the maximum velocity on the horizontal plane moves gradually away from the lance along the direction of the furnace radius. This means that more splashes tend to appear in the region close to the furnace sidewall. On the horizontal planes of $0.7 \mathrm{~m}$ and $1.2 \mathrm{~m}$ above the quiescent bath surface, the distribution of the flue gas and splashing velocity along the furnace radius is relatively uniform, and fluctuates slightly with the variation of the lance immersion depth. 


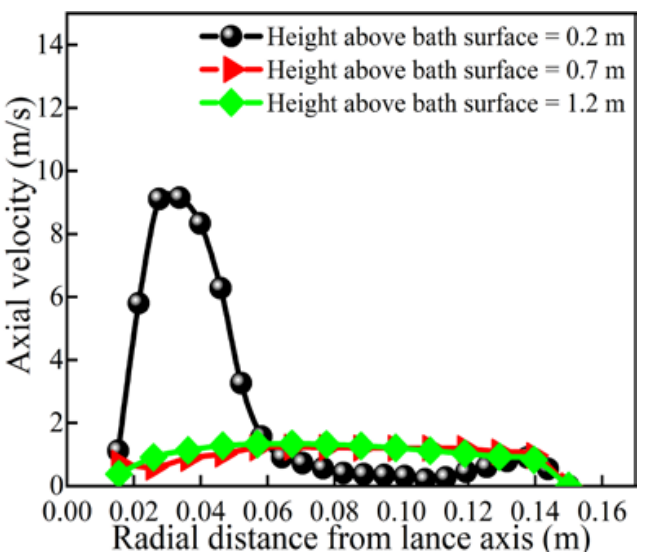

(a)

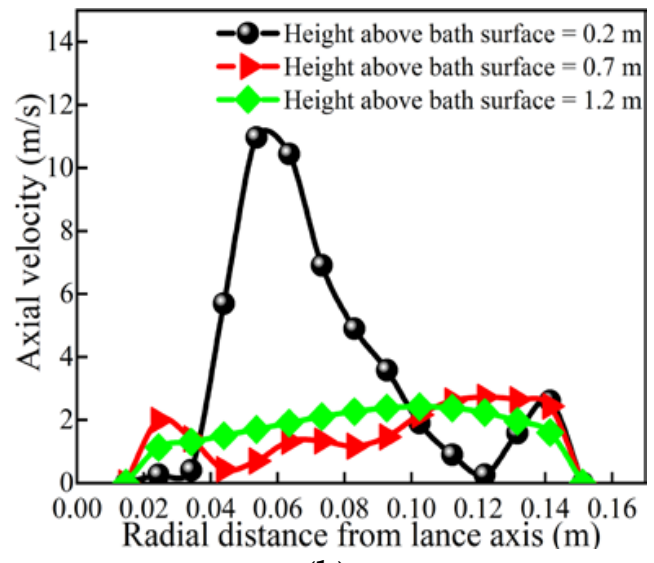

(b)

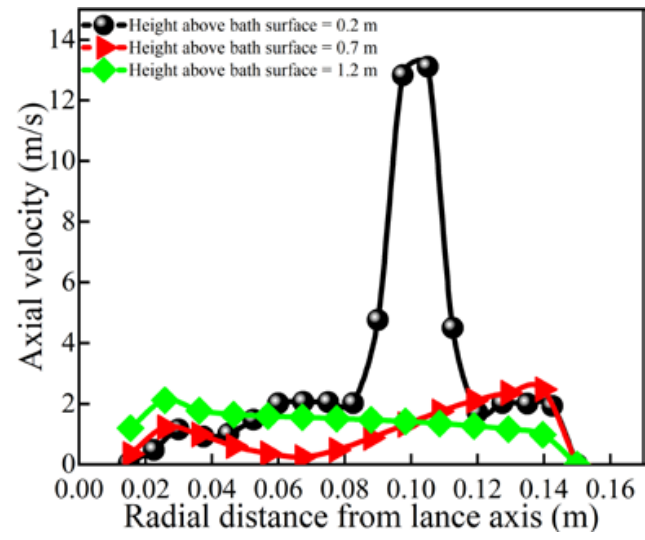

(c)

Figure 8. Influence of lance immersion depth on the distribution of axial velocity of flue gas and splashes along the furnace radius on the horizontal plane at different heights above the quiescent bath surface for the same injection gas flowrate $\left(73 \mathrm{Nm}^{3} / \mathrm{h}\right.$ ). (a) $\mathrm{H}_{\mathrm{L}}=0.10 \mathrm{~m}$, (b) $\mathrm{H}_{\mathrm{L}}=0.15 \mathrm{~m}$, (c) $\mathrm{H}_{\mathrm{L}}=0.20 \mathrm{~m}$.

\subsubsection{Influence of Injection Gas Flowrate on Splash Amount and Distribution}

Figure 9 shows the splash distribution with constant lance immersion but different injection gas flowrates. It can be seen from this figure that, with the increase of injection gas flowrate, the splashing becomes more intensive. The larger the injection gas flowrate, the higher the splashes can reach. Nevertheless, if compared with Figure $5 c$, the effect of injection gas flowrate on the splash generation and distribution is not as pronounced as that of the lance immersion depth. Figure $5 \mathrm{c}$ depicts a stronger stirring effect in the bottom region of the molten bath, whereas Figure 9c indicates a rather limited stirring effect in the same region. Therefore, in actual production, the splash height and amount can be effectively controlled by manipulating the lance immersion depth and, to a lesser extent, by adjusting the injection gas flowrate.

Figure 10 shows the average volume fraction at different heights of the furnace for the same lance immersion depth $(0.15 \mathrm{~m})$ and different injection gas flowrates. We can see that, for the same lance immersion depth, when the injection gas flowrate is set at $56 \mathrm{Nm}^{3} / \mathrm{h}, 73 \mathrm{Nm}^{3} / \mathrm{h}$ and $95 \mathrm{Nm}^{3} / \mathrm{h}$, most of the splashes reach nearly $0.98 \mathrm{~m}, 1.15 \mathrm{~m}$ and $1.57 \mathrm{~m}$, respectively, in height. A few splash droplets can even hit the furnace roof when the injection gas flowrate is $95 \mathrm{Nm}^{3} / \mathrm{h}$. Therefore, in addition to the lance immersion depth, the injection gas flowrate is also a parameter for controlling the splash amount and maximum height. 


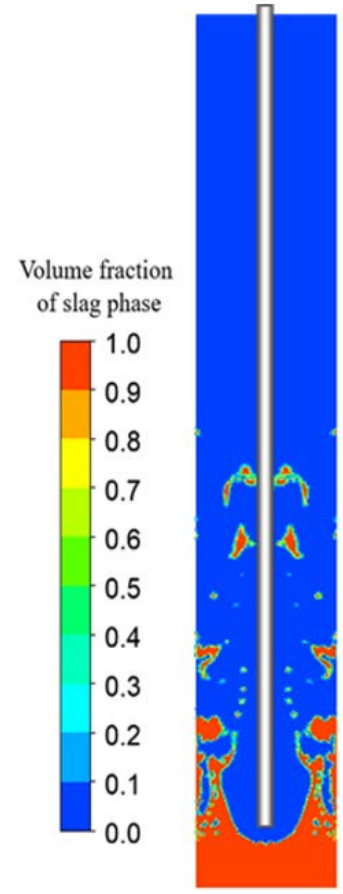

(a)

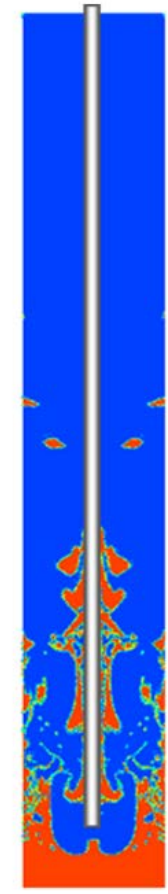

(b)

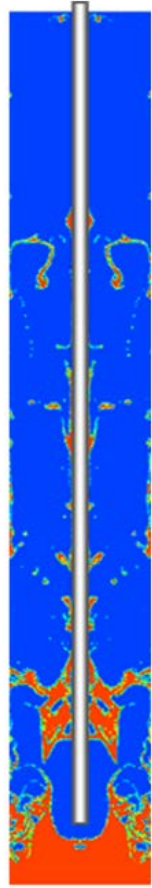

(c)

Figure 9. Splash distribution in TSL furnace for the same lance immersion depth $(0.15 \mathrm{~m})$ and different gas flowrates. (a) $\mathrm{Q}=56 \mathrm{Nm}^{3} / \mathrm{h}$, (b) $\mathrm{Q}=73 \mathrm{Nm}^{3} / \mathrm{h}$, (c) $\mathrm{Q}=95 \mathrm{Nm}^{3} / \mathrm{h}$.

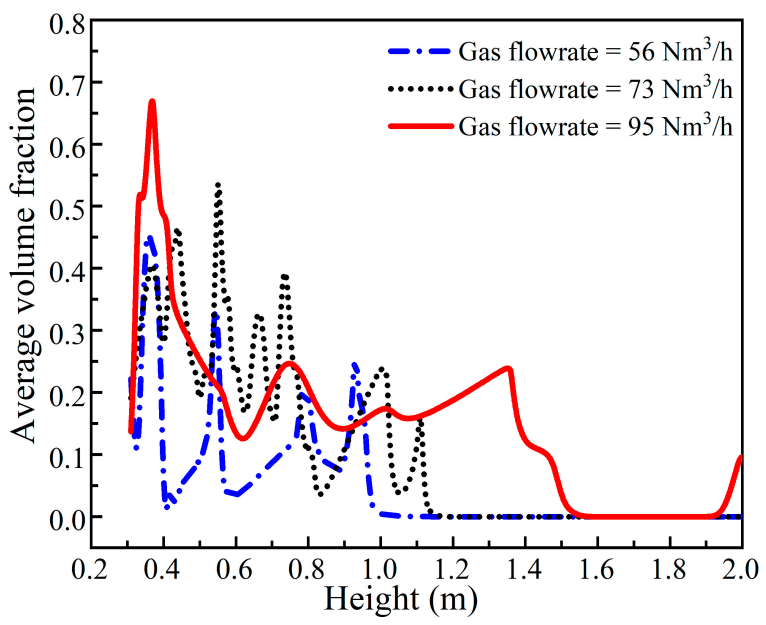

Figure 10. Influence of injection gas flowrate on distribution of average volume fraction of splash along furnace height for the same lance immersion depth $(0.15 \mathrm{~m})$.

Figure 11 shows the effect of the injection gas flowrate on splash amount index (area below each curve shown in Figure 10) for the same lance immersion depth. It can be seen from this figure that the splash amount index increases with the increase of the injection gas flowrate. When the injection gas flowrate increases from $56 \mathrm{Nm}^{3} / \mathrm{h}$ to $73 \mathrm{Nm}^{3} / \mathrm{h}$, the splash amount index increases by $0.0065 \mathrm{~m}^{2}$ (i.e., from $0.0368 \mathrm{~m}^{2}$ to $0.0433 \mathrm{~m}^{2}$ ). However, further increasing the injection gas flowrate to $95 \mathrm{Nm}^{3} / \mathrm{h}$ results in limited increment of the splash amount index. Thus, with the increase of injection gas flowrate, the splash amount index first increases sharply and then tends to level off when the injection gas flowrate is higher than a certain level (e.g., $73 \mathrm{Nm}^{3} / \mathrm{h}$ ). 


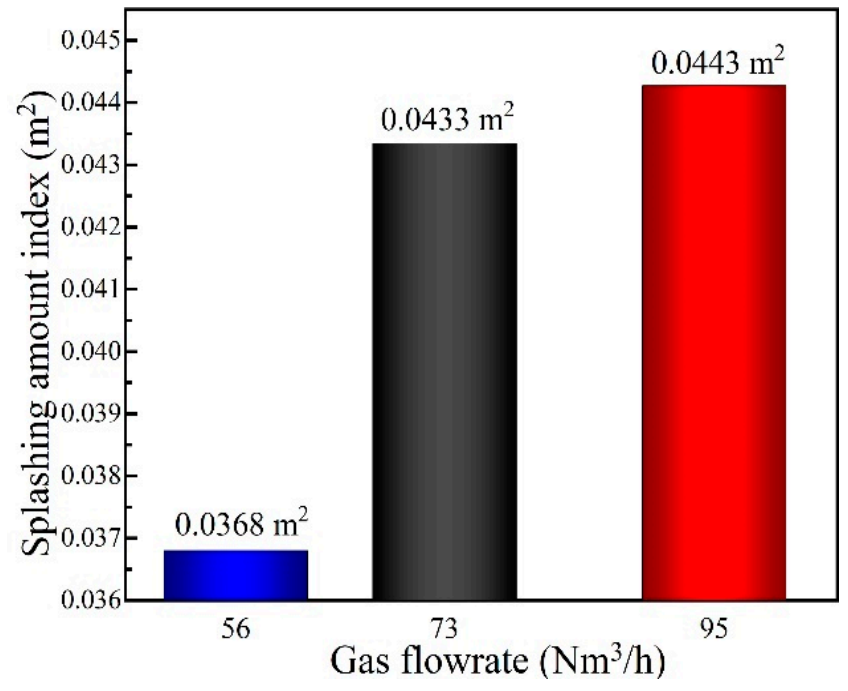

Figure 11. Effect of injection gas flowrate on slag splashing amount index.

Figure 12 shows variation in distribution characteristics of axial velocity of flue gas and splash along the furnace radius on the horizontal plane at different heights above the quiescent bath surface for the same lance immersion depth $(0.15 \mathrm{~m})$ and different injection gas flowrates. When the injection gas flowrate is low $\left(56 \mathrm{Nm}^{3} / \mathrm{h}\right)$, the maximum velocity on a horizontal plane of $0.2 \mathrm{~m}$ above the quiescent bath surface is $9.2 \mathrm{~m} / \mathrm{s}$. It can be seen further from Figure 12 that with the increase of injection gas flowrate from $56 \mathrm{Nm}^{3} / \mathrm{h}$ to $95 \mathrm{Nm}^{3} / \mathrm{h}$, the maximum flue gas and splash velocity on the same horizontal plane increases to $23.5 \mathrm{~m} / \mathrm{s}$. The peaks of the velocity all appear on the level at a lower height $(0.2 \mathrm{~m})$ above the quiescent bath surface and close to the injection lance. However, further up from the quiescent bath surface, e.g., at the levels of $0.7 \mathrm{~m}$ and $1.2 \mathrm{~m}$, the influence of the injection gas flowrate on the distribution of flue gas and splash velocity along the radius of the furnace becomes relatively limited.

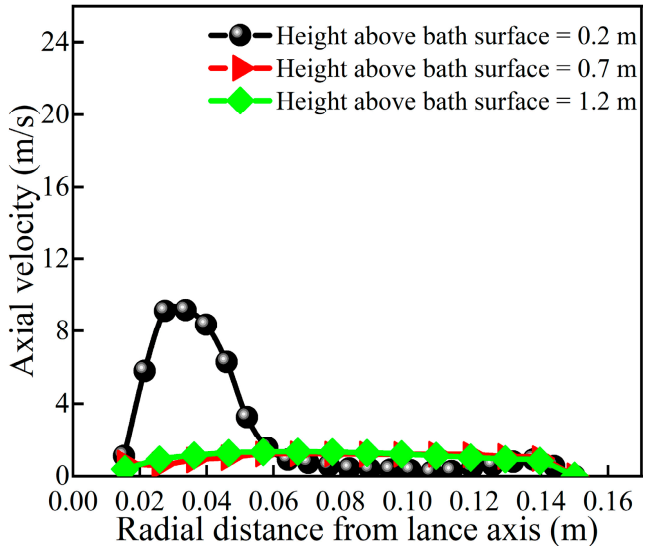

(a)

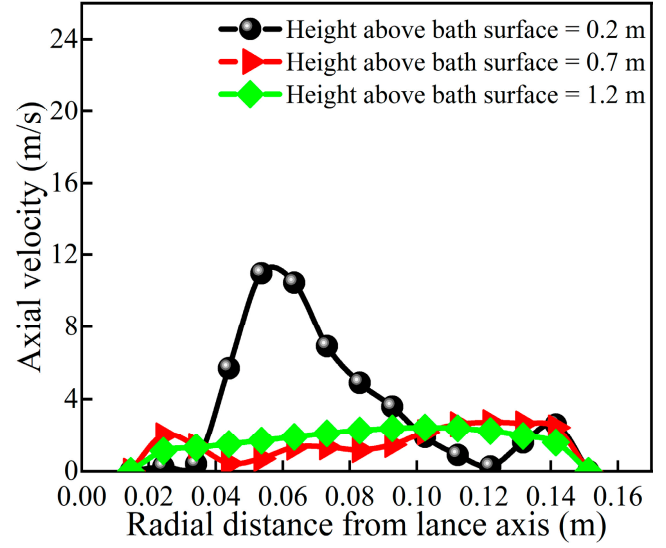

(b)

Figure 12. Cont. 


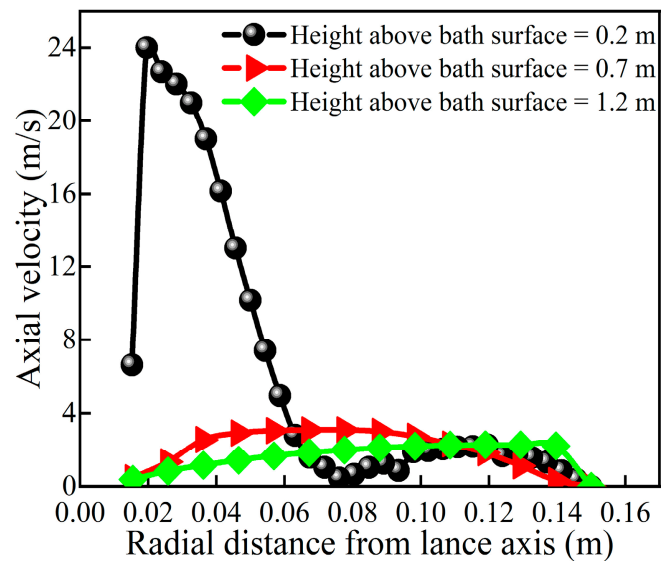

(c)

Figure 12. Influence of injection gas flowrate on the distribution in axial velocity of flue gas and splash along the furnace radius on the horizontal plane at different heights above the quiescent bath surface for the same lance immersion depth $(0.15 \mathrm{~m})$. (a) $Q=56 \mathrm{Nm}^{3} / \mathrm{h}$, (b) $\mathrm{Q}=73 \mathrm{Nm}^{3} / \mathrm{h}$, (c) $\mathrm{Q}=95 \mathrm{Nm}^{3} / \mathrm{h}$.

\subsection{Influence of Operation Parameters on Heat Transfer}

\subsubsection{Influence of Lance Immersion Depth on Temperature Field}

Figure 13 shows the contour plots of temperature distribution in the pilot TSL furnace for the same injection gas flowrate $\left(73 \mathrm{Nm}^{3} / \mathrm{h}\right)$ and different lance immersion depths. In this figure the black color lines stand for liquid-gas interfaces. It can be seen from this figure that the combustion process mainly takes place inside bubbles enveloping the lance tip, and the bubble shape and the combustion reaction components inside the bubbles change dynamically. At high temperature, the flame zone changes with the deformation of the bubbles. When the high temperature bubbles rupture, the flue gas carries the slag splashes and transfers heat to the upper space of the furnace. With the increase of the lance immersion depth, the combustion reaction takes place deeper in the melt bath and the resultant splash distribution is more uniform in the furnace top space, so that the heat transfer between the combustion flue gas and the slag splashes is enhanced. Figure $13 \mathrm{c}$ also depicts that, compared with the splash distributions and temperature fields for the lance immersion depths of $0.10 \mathrm{~m}$ and $0.15 \mathrm{~m}$, c.f., Figure $13 \mathrm{a}, \mathrm{b}$, the splash distribution is more uniform for the lance immersion depth of $0.20 \mathrm{~m}$, which is favorable for achieving more complete heat exchange between the splashed slag and the high-temperature flue gas. After the slag splashes eventually fall back to the bath, more heat is transferred from the flue gas to the molten bath, and the heat transfer efficiency of the TSL furnace is effectively improved. Contrary to Figure 13c, Figure 13a shows that the bath stirring is poor, the splash amount is less and its distribution is not uniform, so that the heat exchange between the splashed slag and flue gas is rather limited, leading to higher flue gas temperature in the furnace top space. As a result, the heat transfer from the flue gas to the molten bath is less and the heat transfer efficiency of the furnace is low.

Figure 14 shows the variation in the average temperature of the flue gas at the outlet of the TSL furnace with the increase of the lance immersion depth when the gas flowrate is kept at $73 \mathrm{Nm}^{3} / \mathrm{h}$. As seen, when the lance immersion depth is increased from $0.10 \mathrm{~m}$ to $0.20 \mathrm{~m}$, the average temperature of the flue gas flowing out of the furnace decreases from $1472 \mathrm{~K}$ to $1274 \mathrm{~K}$. The reason is that, as indicated by Figure 13, with a deeper lance immersion depth, the bath stirring is intensified, so that the splashed slag is more evenly distributed in the furnace top space with increased contact area between the splashes and the high-temperature flue gas, which enhances the heat being transferred from the high-temperature flue gas to the slag splashes, resulting in decreased flue gas temperature at the furnace outlet. 


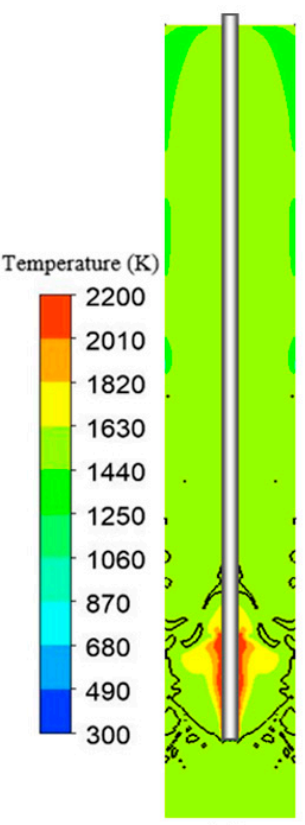

(a)

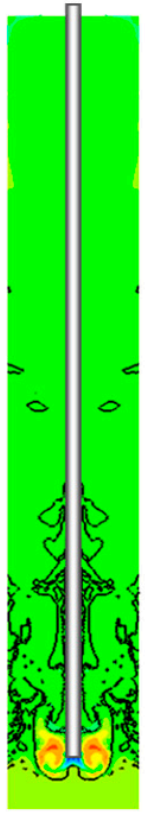

(b)

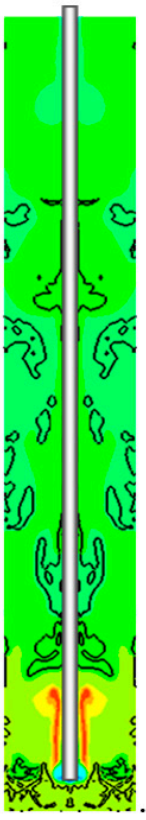

(c)

Figure 13. Temperature distribution contours in TSL furnace for the same injection gas flowrate $\left(73 \mathrm{Nm}^{3} / \mathrm{h}\right.$ ) and different lance immersion depths. (a) $\mathrm{H}_{\mathrm{L}}=0.10 \mathrm{~m},(\mathbf{b}) \mathrm{H}_{\mathrm{L}}=0.15 \mathrm{~m},(\mathbf{c}) \mathrm{H}_{\mathrm{L}}=0.20 \mathrm{~m}$.

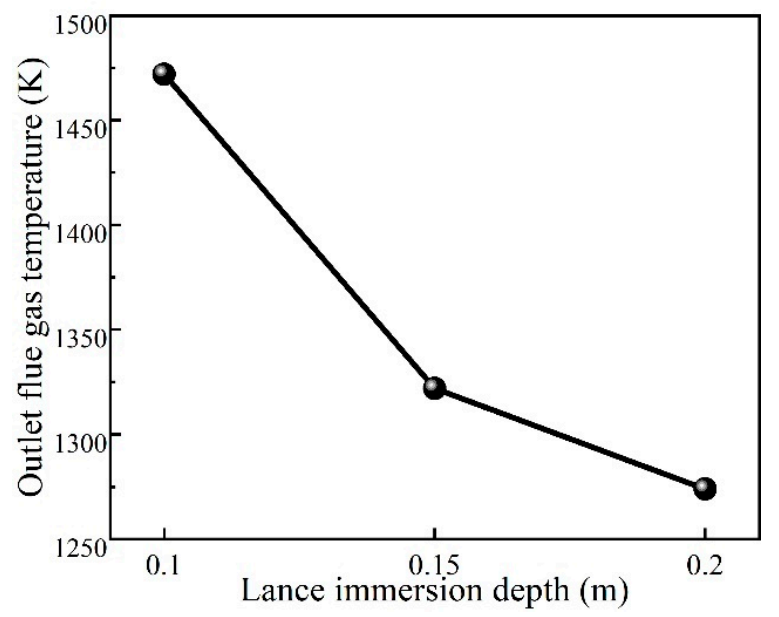

Figure 14. Influence of lance immersion depth on average temperature of flue gas at furnace outlet.

\subsubsection{Influence of Injection Gas Flowrate on Temperature Field}

Figure 15 shows contour plots of temperature distribution in TSL furnace for the same lance immersion depth $(0.15 \mathrm{~m})$ and different injection gas flowrates. In this figure the black color lines again stand for liquid-gas interfaces. It can be seen from this figure that, in general, the furnace gas phase temperature decreases with the increase of the injection gas flowrate. When the injection gas flowrate is $56 \mathrm{Nm}^{3} / \mathrm{h}$, there exist larger high-temperature zones than those for higher injection gas flowrates; when the injection gas flowrate are $73 \mathrm{Nm}^{3} / \mathrm{h}$ and $95 \mathrm{Nm}^{3} / \mathrm{h}$, the temperature distribution is more uniform than that for injection gas flowrates of $56 \mathrm{Nm}^{3} / \mathrm{h}$. The reason is that when the injection gas flowrate is low, the molten bath is not fully stirred, the splash distribution is uneven, resulting in limited heat exchange between splashes and high temperature flue gas, which leads to the flue gas carrying more heat out of the furnace. 


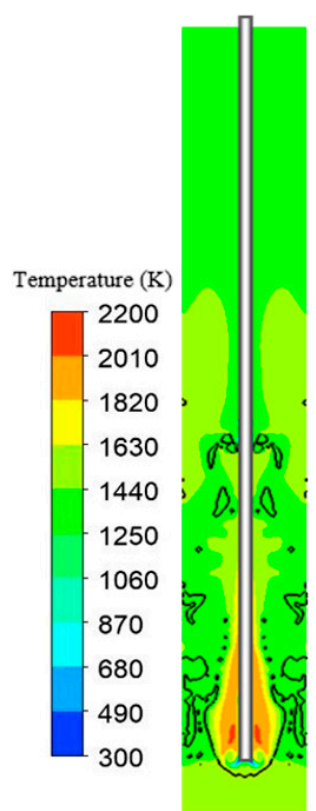

(a)

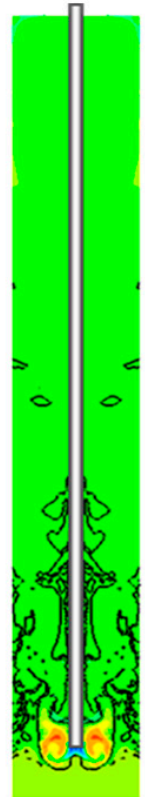

(b)

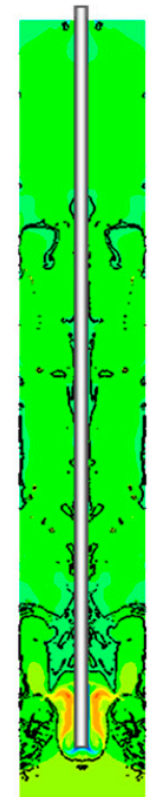

(c)

Figure 15. Temperature distribution contours in TSL furnace for the same lance immersion depth $(0.15 \mathrm{~m})$ and different injection gas flowrates. (a) $\mathrm{Q}=56 \mathrm{Nm}^{3} / \mathrm{h},(\mathbf{b}) \mathrm{Q}=73 \mathrm{Nm}^{3} / \mathrm{h}$, (c) $\mathrm{Q}=95 \mathrm{Nm}^{3} / \mathrm{h}$.

Figure 16 shows the influence of injection gas flowrate on the average temperature of flue gas at the furnace outlet for the same lance immersion depth $(0.15 \mathrm{~m})$. It can be seen from this figure that with the increase of injection gas flowrate, the flue gas temperature at the furnace outlet decreases. With the further increase of the injection gas flowrate, the temperature drop of the flue gas flowing out of the furnace slows down. Therefore, in the actual production process, there is an appropriate range in injection gas flowrate to achieve the best heat transfer efficiency.

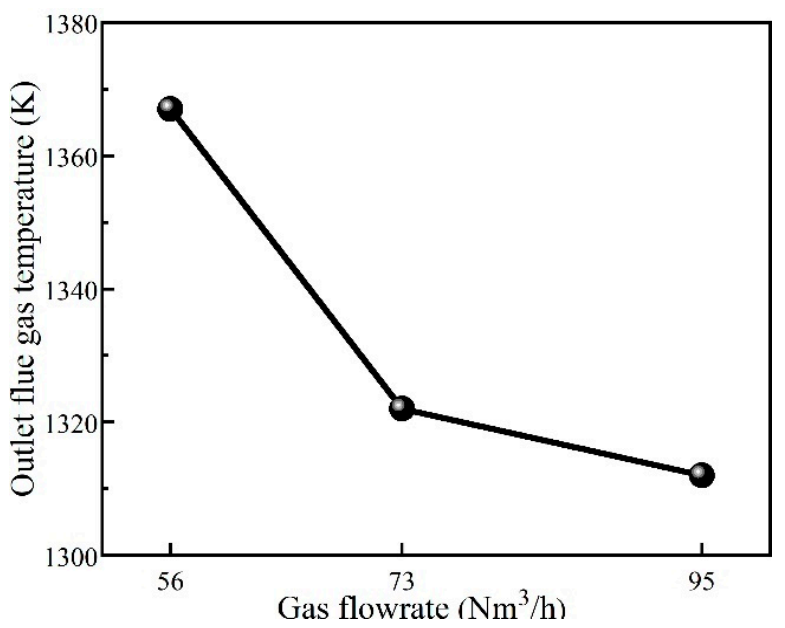

Figure 16. Influence of injection gas flowrate on average temperature of flue gas at furnace outlet.

\subsection{Model Limitations}

While the numerical simulation results discussed in the preceding sections provide an in-depth understanding of bubble behavior, splash generation and heat transfer characteristics due to submerged injection and combustion in TSL furnaces, the present CFD model still suffers from, among others, the following limitations:

Slag foaming effect: As an assumption, the present model neglects the slag foaming phenomenon. Nevertheless, it is well known that slag foaming is rather a common phenomenon occurring in TSL furnaces. The fine bubbles generated from chemical reactions 
between slag and metal or matte are trapped in the slag layer, which causes formation of a slag foam that likely possesses themophysical properties (such as density, viscosity, thermal conductivity, etc.) that are different from the pure slag, which may lead to different splashing behavior and heat transfer characteristics. Therefore, the slag foaming phenomenon will be considered in our future modeling work.

VOF model limitation: The VOF model was used in the present simulation work to track the liquid-gas two-phase interfaces. However, this approach requires enough fine grids to resolve each phase. If the length scale of any phase is too small, just like fine bubbles dispersed in liquid slag to form a foam, the VOF model would become inadequate for simulating such a case due to the unaffordable computation amount. In this regard, the population balance model could have advantages in dealing with the dispersion of small bubbles in a continuous phase like a slag foam. This aspect deserves further study in the future.

Model validation limitation: The present CFD model was only qualitatively validated using experimental observations from a cold physical model reported in literature [9]. It would be ideal that the CFD model should have been validated against the direct observations on the splashing phenomenon in a high-temperature TSL furnace and, even better, the measured splash quantities sampled from the furnace. Unfortunately, the harsh environment inside a high-temperature TSL furnace generally makes it extremely hard to facilitate direct observation and measurement. Instead, measuring the exit gas temperature as a function of gas flowrate and lance immersion depth could be relatively easily applicable and thus will be practiced in our future work.

\section{Conclusions}

In this study, influences of the lance immersion depth and total injection gas flowrate on the splashing behavior and heat transfer during submerged injection and combustion in a $300 \mathrm{~kg}$ pilot TSL furnace were investigated using the two-dimensional CFD simulation technique. The following conclusions can be drawn from the present study:

1. Compared with cold simulation systems of TSL furnaces, the bubbles generated in high temperature systems due to combustion are much larger and the splash height when the bubbles break is much higher than that of the cold system under the same operating conditions.

2. With the increase of the lance immersion depth, the gas injection and combustion impacts on larger volumes of the slag bath and thus intensifies bath agitation, leaving less dead zone. Accordingly, more slag splashes can be generated with more uniform distribution in the furnace top space above the bath; this will lead to more efficient heat transfer between the splashed slag and the high-temperature flue gas, so that heat transfer efficiency in the furnace is improved.

3. With the increase of injection gas flowrate, the slag splash amount first increases significantly and then its effect on the splash amount becomes weak. When the injection gas flowrate is larger than a critical level, its effect on bath stirring becomes limited, leaving a relatively larger dead zone in the bath.

4. Too low injection gas flowrate leads to too weak and nonuniform splash generation, whereas too high injection gas flowrate allows short residence time for the flue gas to exchange heat with the splashed slag inside the furnace, both of which result in poor heat transfer efficiency of the furnace. Therefore, there exists an appropriate range in injection gas flowrate for achieving sufficiently high heat transfer efficiency in a TSL furnace.

5. The splash amount and distribution inside the furnace top space can be strongly influenced by the lance immersion depth and, to a lesser degree, by the injection gas flowrate, and the maximum splash height and heat transfer can be controlled by adjusting the lance immersion depth and the injection gas flowrate. 
Author Contributions: Conceptualization, C.S. and Y.P.; methodology, C.S. and Y.P.; validation, C.S. and Y.P.; formal analysis, C.S. and Y.P.; investigation, C.S.; resources, Y.P. and P.M.; data curation, C.S. and Y.P.; writing-original draft preparation, C.S.; writing-review and editing, Y.P., P.M., M.Z. and T.L.; visualization, C.S.; supervision, Y.P. and P.M.; project administration, M.Z.; funding acquisition, Y.P. and P.M. All authors have read and agreed to the published version of the manuscript.

Funding: This research received no external funding.

Data Availability Statement: Data supporting reported results can be found in this paper.

Acknowledgments: The authors would like to thank University of Science and Technology Liaoning, China, for financial support of the present work.

Conflicts of Interest: The authors declared that they have no conflicts of interest to this work.

\section{Nomenclature}

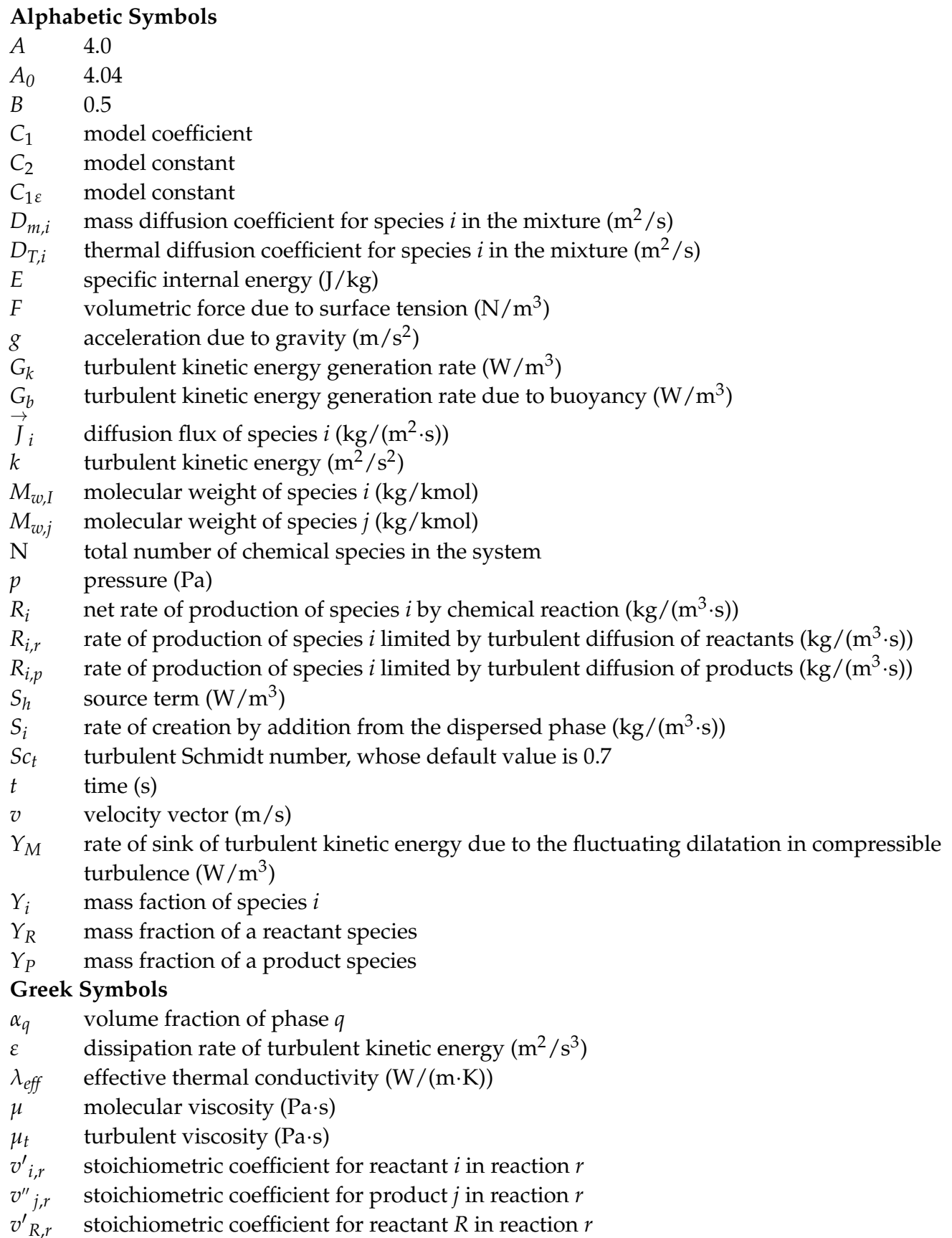




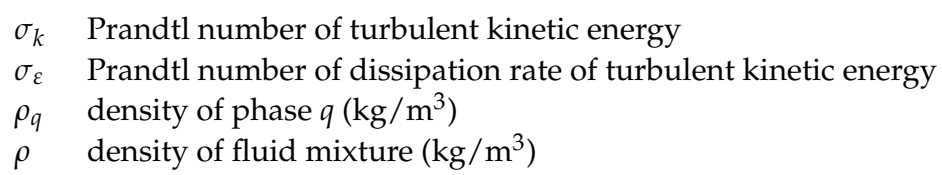

\section{References}

1. Zhang, J.P. Status and development of metallurgical solid waste resource utilization. Nonferrous Met. Eng. Res. 2020, 41, 39-42. (In Chinese)

2. Floyd, J.M. Converting an idea into a worldwide business commercializing smelting technology. Met. Mater. Trans. B. 2005, 36, 557-575. [CrossRef]

3. Hoang, J.; Reuter, M.; Matusewicz, R.; Hughes, S.; Piret, N. Top submerged lance direct zinc smelting. Miner. Eng. 2009, 22, 742-751. [CrossRef]

4. Bakker, M.L.; Nikolic, S.; Mackey, P.J. ISASMELT ${ }^{\text {TM }}$ TSL-Applications for nickel. Min. Eng. 2011, 24, 610-619. [CrossRef]

5. Degterov, S.A.; Pelton, A.D. A thermodynamic database for copper smelting and converting. Met. Mater. Trans. B. 1999, 30, 661-669. [CrossRef]

6. Wang, X.; Cao, H. Exploration on industrialization development path of comprehensive utilization of solid waste in iron and steel industry. China Resour. Compr. Util. 2019, 37, 60-62. (In Chinese)

7. Liovic, P.; Liow, J.L.; Rudman, M.A. Volume of Fluid (VOF) method for the simulation of metallurgical flows. ISIJ Int. 2001, 41, 225-233. [CrossRef]

8. Liovic, P.; Rudman, M.; Liow, J.L. Numerical modelling of free surface flows in metallurgical vessels. Appl. Math. Model. 2002, 26, 113-140. [CrossRef]

9. Pan, Y.; Langberg, D. Two-dimensional physical and CFD modelling of large gas bubble behaviour in bath smelting furnaces. $J$. Comput. Multip. Flows. 2010, 2, 151-164. [CrossRef]

10. Wang, S.B.; Wang, H.; Xu, J.X.; Zhu, D.F.; Sun, H.; Li, H.J. Hot-state numerical simulation study on top-blown bath in Isa furnace. Adv. Mater. Res. 2011, 383-390, 7406-7412. [CrossRef]

11. Huda, N.; Naser, J.; Brooks, G.; Reuter, M.; Matusewicz, R. CFD modeling of swirl and nonswirl gas injections into liquid baths using top submerged lances. Met. Mater. Trans. B 2009, 41, 35-50. [CrossRef]

12. Huda, N.; Naser, J.; Brooks, G.; Reuter, M.A.; Matusewicz, R.W. Computational fluid dynamic modeling of zinc slag fuming process in top-submerged lance smelting furnace. Met. Mater. Trans. B. 2011, 43, 39-55. [CrossRef]

13. Kolczyk, E.; Miczkowski, Z.; Czernecki, J. Influence of selected parameters on phenomena of two-phase flow and heat ex-change in TSL furnace-numerical investigation. Int. J. Numer. Methods Heat Fluid Flow. 2017, 27, 2799-2815. [CrossRef]

14. Yin, P.; Zhao, H.L.; Zhang, L.; Wang, S.; Zhang, J.; Fan, W. Numerical simulation of Isa smelting process with top swirl blowing. J. Mater. Metall. 2017, 16, 104-109. (In Chinese)

15. Zhao, H.; Lu, T.; Yin, P.; Mu, L.; Liu, F. An experimental and simulated study on gas-liquid flow and mixing behavior in an ISASMELT furnace. Metals 2019, 9, 565. [CrossRef]

16. Zhao, H.; Xiao, Y.; Liu, F.; Sohn, H.Y. Computational fluid dynamics simulation of gas-matte-slag three-phase flow in an ISASMELT furnace. Met. Mater. Trans. B. 2021, 52, 3767-3776. [CrossRef]

17. Obiso, D.; Kriebitzsch, S.; Reuter, M.; Meyer, B. The importance of viscous and interfacial forces in the hydrodynamics of the top-submerged-lance furnace. Met. Mater. Trans. B. 2019, 50, 2403-2420. [CrossRef]

18. Obiso, D.; Akashi, M.; Kriebitzsch, S.; Meyer, B.; Reuter, M.; Eckert, S.; Richter, A. CFD modeling and experimental validation of top-submerged-lance gas injection in liquid metal. Met. Mater. Trans. B. 2020, 51, 1509-1525. [CrossRef]

19. Sabah, S.; Brooks, G. Splash distribution in oxygen steelmaking. Met. Mater. Trans. B. 2014, 46, 863-872. [CrossRef]

20. Hirt, C.W.; Nichols, B.D. Volume of fluid (VOF) method for the dynamics of free boundaries. J. Comput. Phys. 1981, 39, 201-225. [CrossRef]

21. Brackbill, J.U.; Kothe, D.B.; Zemach, C. A continuum method for modeling surface tension. J. Comput. Phys. 1992, 100, 335-354. [CrossRef]

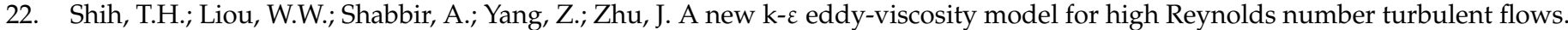
Comput. Fluids. 1995, 24, 227-238. [CrossRef]

23. ANSYS Inc. ANSYS CFD User's Manual; ANSYS Inc.: Canonsburg, PA, USA, 2013. 